\title{
Sensorless Starting of Direct Drive Horizontal Axis Washing Machines
}

\author{
Anton Dianov, Nam Su Kim and Seung Moo Lim
}

\begin{abstract}
This paper describes problems of the sensorless starting of horizontal axis washing machines with direct drive and suggests solution, which was experimentally verified. Horizontal axis washing machines have very difficult conditions for the drive starting, especially at full load. Inertia of the tub and water, torque from the laundry make load torque at starting higher than rated one and sometimes even higher than the maximum torque of the motor, which makes sensorless starting extremely challenging task. This paper suggests modified open-loop starting, where control system is closed shortly after beginning at low speed and rotates the drum until laundry restructuring. To ensure proper work of the sensorless algorithm at low speed additional measures for increasing of the estimation algorithm performance have been taken. These measures include special algorithm for the drive parameters estimation, which has been developed and verified by the experimental results.
\end{abstract}

Keywords: Washing Machine, Sensorless Algorithm, Direct Drive, Parameters Estimation

\section{Introduction}

Nowadays makers of the washing machines develop two types of the motor drives. The first one is belted, where motor is connected to the drive with the belt; and the second is Direct Drive (DD), where rotor is mounted on the tub and there are no any transmissions. Direct drives have advantage of saving space and benefits of the efficiency and reliability however they are more difficult to control and complicated in assembling. Every change in load, like laundry restructuring or eccentricity, directly affects the motor and sometimes can even damage it. So direct drive control system has to be carefully elaborated and verified.

Washing machine direct drives are usually based on the Permanent Magnet Synchronous Motor (PMSM), which means that they have to contain position sensor or position estimation algorithm, since this information is essential for the control system. The most popular solution is to attach low resolution hall sensor, which typically has two channels and outputs two pulses per electrical revolution [3]. These signals are processed by the estimation algorithm, which estimates speed and rotor position between pulse edges. Previously this solution was compromise between price and quality, but with the development of microcontrollers and algorithms there is a tendency of position sensors elimination, which saves money and increases device

Motor Group, Samsung Electronics(anton.dianov@samsung.com)

Received 11 April 2014; Accepted 23 April 2014 reliability.

Nowadays a lot of home appliances makers pay their attention to the migration from sensed to sensorless motor control. In this area some researches have been successfully performed and many drives for refrigerators, air conditioners, etc., are producing with the sensorless modification. However there are several types of the drive, where sensorless modification is very challenging task and many scientists try to solve this problem. Usually these drives are low-speed ones or drives with difficult load condition, where load torque changes fast and in the wide range, sometimes exceeding motor maximum torque. It significantly disturbs sensorless control system and sometimes can fail it. The most problematic drives for the development of the sensorless control system are drives for tools like drills, saws, etc., or direct drive for washing machines with horizontal axis.

\section{Starting Problem}

The main problem for the PMSM sensorless drives is starting and rotation at low speed. When the motor works in the middle and high speed range, the back-EMF induced in its windings is considerable and applied voltage is also large, so they are the most significant terms of the motor model. It means that motor parameters variation and measurement errors do not affect model significantly, so speed and position estimation errors are small. In the low speed range motor back-EMF and applied voltages are small, so motor model is strongly affected by the measurement errors and variation of the motor parameters. 
To solve this problem some researchers $[4,5]$ suggest high-frequency injection based methods, which work well even at zero speed. However such methods depend on the difference between direct and quadrature inductances and the closer inductances to each other are the greater amplitude of the tested current signal should be applied. But with the increase of the high frequency current acoustic noises produced by the injection gets louder and more irritating. So this solution is not applicable for the home appliances and control system has to utilize flux-based or back-EMF based estimator and to solve the problem of poor estimation at zero speed.

During recent years several studies have been devoted to this problem and some solutions have been proposed. Authors of [2] proposed to use direct flux control, which results in fast response, but need high commutation PWM frequency ( $16 \mathrm{kHz}$ reported) and has disadvantage of increased noises. Authors of [6] involved flux based motor model for the conventional control scheme, which allow commutation at lower frequency. One more interesting method is sliding mode observer, which was reported in [1]. This method has good robustness, but for better performance it has to operate at high frequency. Authors of [1] reported switching frequency of $20 \mathrm{kHz}$, but it is higher than for other methods and significantly increases losses decreasing drive performance.

As a part of this project many works dedicated to the $\mathrm{H}$ axis washing machines have been studied, but almost no one reported about starting problem, which is very important for the development of the high load and high efficiency washing machines. Starting problem for

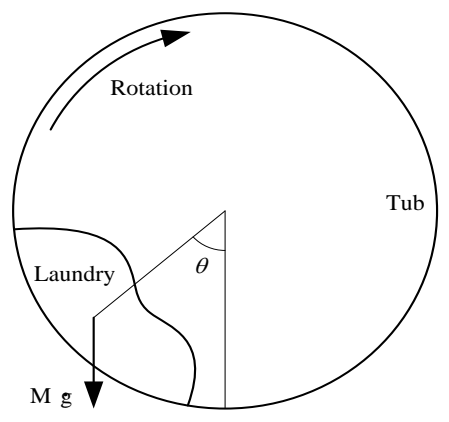

Fig. 1. Laundry load of the horizontal axis washing machine

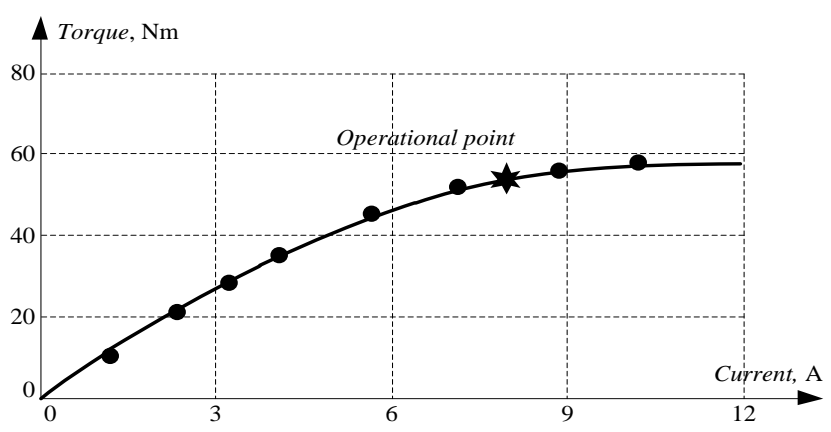

Fig. 2. Motor torque horizontal axis washing machines is illustrated in Fig. 1. Before starting the laundry is at the bottom of the tub and gets pressed. So when rotation starts it behave like a solid, whose load torque depends on the tub angle $\theta$. When the tub rotates at angle close to $110^{\circ}$ the laundry gets restructured and some part of it fells down to the bottom of the tub, and laundry torque decreases. During this rotation cycle until next stop some part of the laundry permanently fells down, so the load torque is significantly less than starting one and this washing mode does not cause any problem. The load torque at starting, when the laundry is unstructured, is significantly higher than the washing torque and can be even higher than the maximum torque of the motor. Furthermore optimal design of the motor has rated operational point close to saturation, $6 \mathrm{~A}$ at Fig. 2, so additional current rise just slightly increases produced torque, and the simplest solution for starting - current increase, does not work here.

The best solutions for this problem is two-stepped starting, when the tub is initially rotates to the direction opposite desired at some angle, i.e. increases its potential energy, and then it starts at the desired direction. This idea helps to overcome starting problem, when the load torque is greater than the motor torque; furthermore it creates soft conditions for the starting of sensorless system. Unfortunately this algorithm was patented by another company and different method has to be elaborated.

To solve this problem motor torque has to be fully utilized and tub has to be accelerated, when the motor torque is greater than the load one; when the laundry torque rises more than motor torque the drive brakes, but its kinetic energy is enough to overcome peak of the load torque and to reach the point of laundry restructuring. This situation is illustrated by the Fig. 3. Kinetic energy stored in the zone 1 is enough to run through the zone 2; at that time motor speed decreases, but remains greater than zero. Starting process in Fig. 3 is drawn without taking laundry restructuring into account. In the real case it happens at the angle close to $110^{\circ}$, load torque decreases and tub speed does not decrease so significant.

However sensorless starting under such conditions is

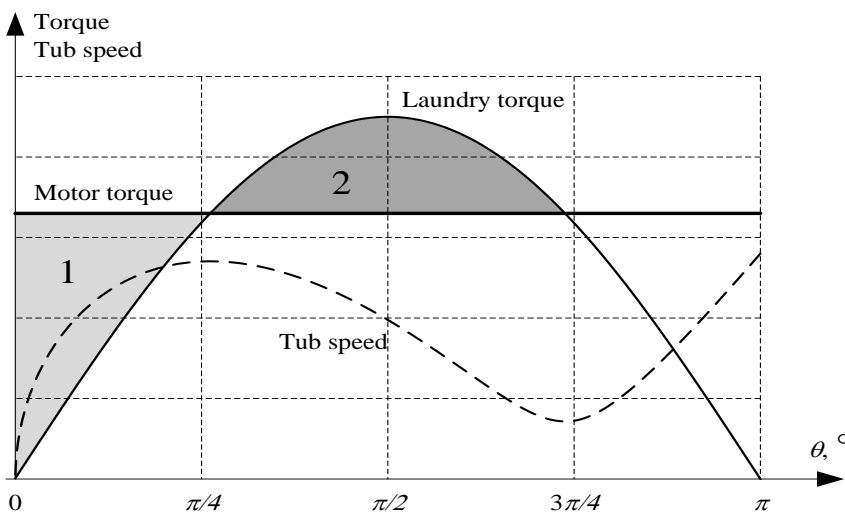

Fig. 3. Desired mechanical characteristics at starting 
very challenging task; control system has to provide maximum torque at the starting, so open-loop system has to be closed as soon as possible and position estimator has to produce low output error.

In this case another problem arises; motor models at low speed are very sensitive to parameters variation, which can be caused by the motor assembly at the factory or working conditions. The stator temperature can significantly vary depending on the washing machine laundry load and washing cycle. This temperature variation considerably impacts on the stator resistance and motor model deteriorating its performance. One more parameter to be taken into account is voltage drop along power switches. This value is about $3 \mathrm{~V}$ and usually is neglected, but it also affect motor model at low speed. At the same time a deadtime compensation algorithm has to be utilized since at low speed dead-time has a great impact on the current waveform and produced torque. Other parameters, which significantly vary at starting, are stator inductances. To minimized operational time in the open loop mode control system applies high current, which causes steel saturation and decrease of the inductances. So their dependence on the current has to be considered for decreasing of the estimation errors and proper implementation of the Maximum Torque Per Ampere (MTPA) control.

\section{Proposed Techniques}

As it was discussed above the control system starts motor in the open loop, and get closed at low speed. To provide high acceleration of the tub, the control system applies maximum current in the open loop mode and, when it gets closed, applies maximum torque. This algorithm needs low

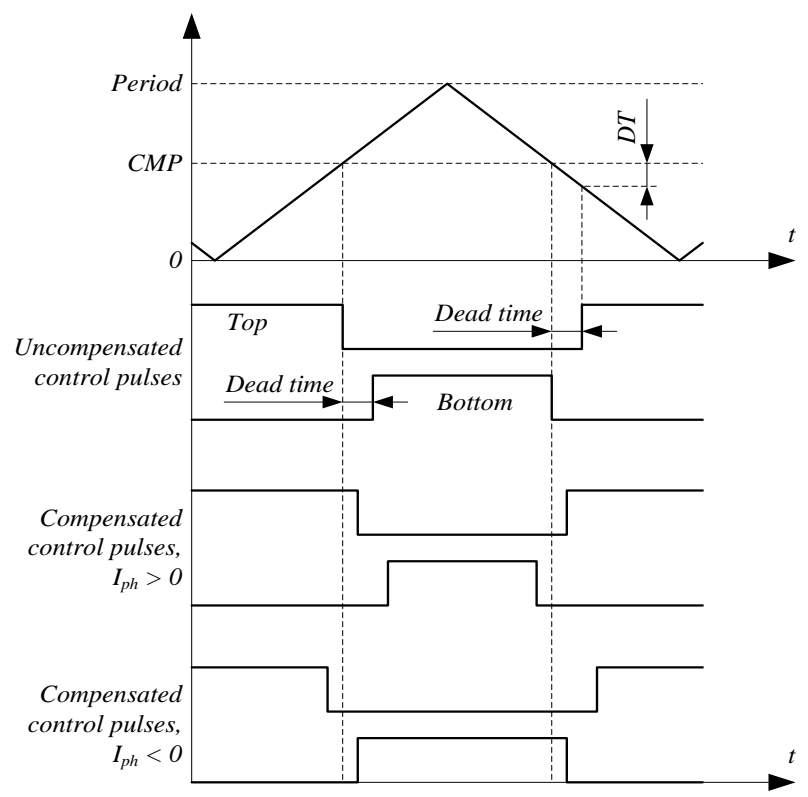

Fig. 4. One phase PWM unit signals position estimation error, so model parameters have to be known with a high precision and their variations have to be taken into account.

\subsection{Stator resistance variation and voltage drop along power switches}

Since stator resistance has a great influence on the motor model at low speed, it should be known precisely. However it significantly varies with the stator temperature change during washing. So for better performance the resistance has to be measured every time before start. For this purpose test DC voltage $U$ is applied to the stator and stator current $I$ is measured. According to the Kirchhoff law:

$$
U=\Delta U_{S W \Sigma}+I R_{\Sigma},
$$

where

$\Delta U_{S W \Sigma}$-total voltage drop along inverter switches,

$R_{\Sigma} \quad$-total resistance.

Total resistance in (1) depends on the states of inverter switches. Neglecting resistance of the wires, $R_{\Sigma}$ can be set equal to $1.5 R_{s}$ or $2 R_{s}$ for "Y" connected windings, where $R_{s}$ is phase resistance. The value of $2 R_{s}$ is more preferable, because such configuration of motor winding provides higher applied voltage with the same level of current. Since (1) contains two unknown variables two different levels of DC voltage have to be applied and two currents have to be measured. It results in the system:

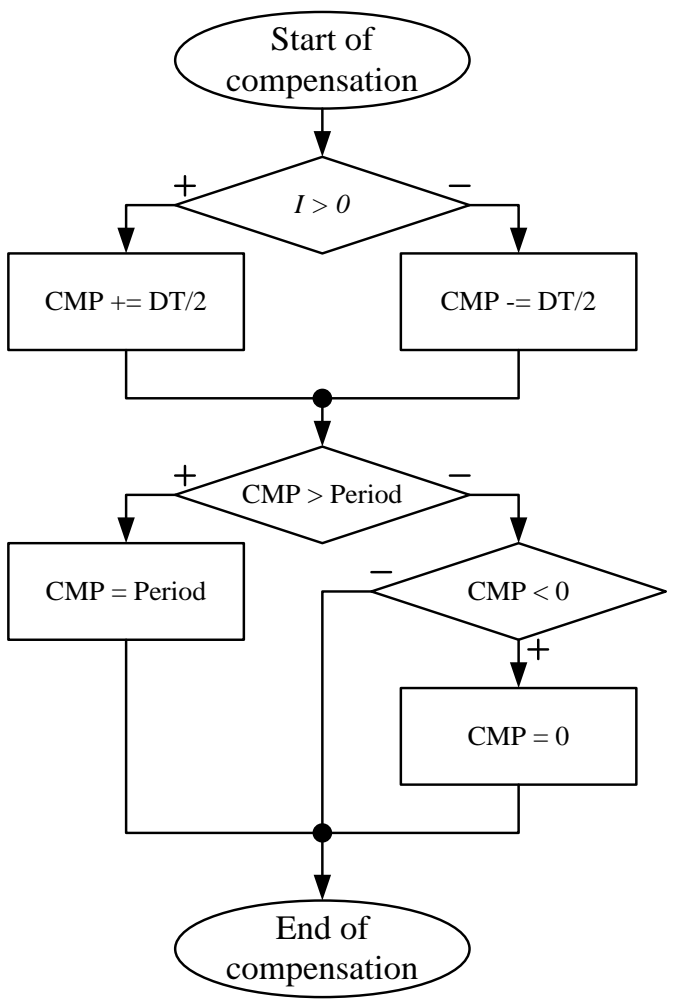

Fig. 5. Dead-time compensation algorithm 


$$
\left\{\begin{array}{l}
U_{1}=\Delta U_{S W \Sigma}+I_{1} R_{\Sigma} \\
U_{2}=\Delta U_{S W \Sigma}+I_{2} R_{\Sigma}
\end{array},\right.
$$

where

$$
\begin{array}{ll}
U_{1}, U_{2}, & \text {-two different voltage levels, } \\
I_{1}, I_{2}, & \text {-currents corresponding to them. }
\end{array}
$$

It can be easily solved for voltage drop and total resistance:

$$
\begin{gathered}
R_{\Sigma}=\frac{U_{1}-U_{2}}{I_{1}-I_{2}}, \\
\Delta U_{S W \Sigma}=\frac{U_{1} I_{2}-U_{2} I_{1}}{I_{2}-I_{1}},
\end{gathered}
$$

After that stator resistance can be found depending on the winding commutation.

\subsection{Dead-time compensation}

As far as voltage applied to the motor at starting is relatively low, command pulses to inverter switches are short. So dead-time, which is typically $1.5-2 \mu \mathrm{s}$, cuts significant parts of the pulses and this part increases with the increase of PWM frequency. This effect adds

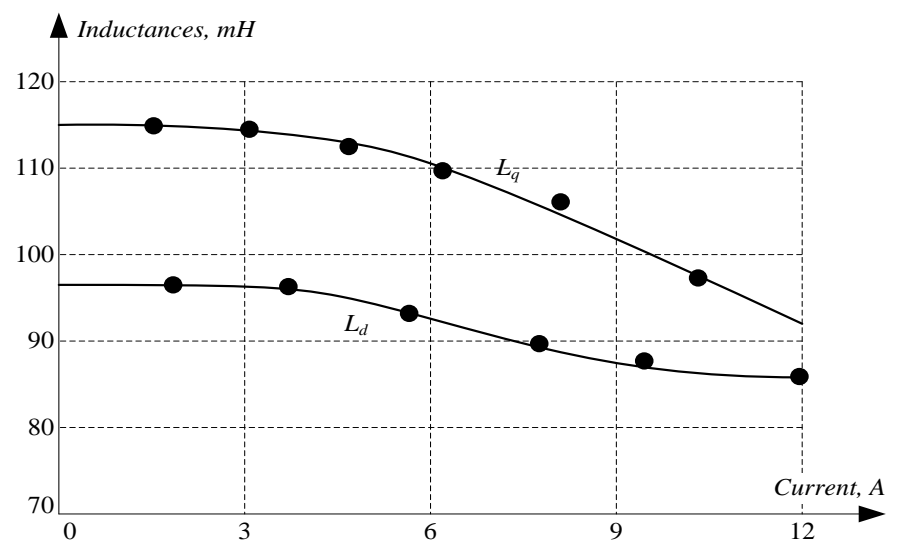

Fig. 6. Motor inductances

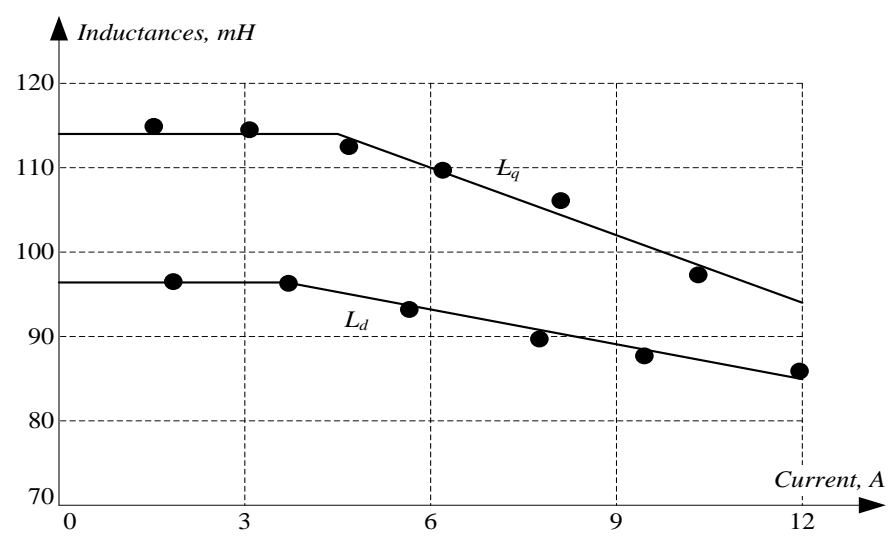

Fig. 7. Approximation of the motor inductances nonlinearity to the control system and considerably distorts current waveform, so it should be compensated for better work of the position estimator.

Dead-time compensation is a popular topic and many papers describe this problem. For the current work the simplest algorithm, which works directly with PWM unit registers has been selected. The signals of typical PWM unit with inverted signals and dead-time insertion at the rising edges are shown in the Fig. 4 and scheme of the algorithm is drawn in the Fig. 5. This algorithm maintains control pulses to have constant width for pulse, which affects phase current, i.e. top switch for positive current and bottom switch for negative one. The corrected pulses have tiny asymmetry relative to the PWM period (half of the dead-time), but it does not significantly affect the current.

\subsection{Inductances variation}

Two more motor parameters, which variations have to be considered, are direct and quadrature inductances. High current at starting saturates steel and changes inductances. Such dependencies for the tested motor are shown in the Fig. 6. For taking this variation into account a simple approximation shown in the Fig. 7 has been proposed. If the current is less than saturation current the inductance is considered to be constant and if the current is greater inductance linearly decreases. It can be described by the expression:

$$
L(i)=\left\{\begin{array}{ll}
L_{0}, & I \leq I_{\text {sat }}, \\
L_{0}-\Delta L\left(i-I_{\text {sat }}\right), & I>I_{\text {sat }}
\end{array},\right.
$$

where

$$
\begin{array}{ll}
L_{0} & \text {-unsaturated inductance, } \\
I_{s a t} & \text {-saturation current. } \\
\Delta L & \text {-inductance drop per ampere. }
\end{array}
$$

Since motor inductances vary they affect MTPA angle of the motor. This change also has to be taken into account for the producing of the maximum torque. MTPA curve for the

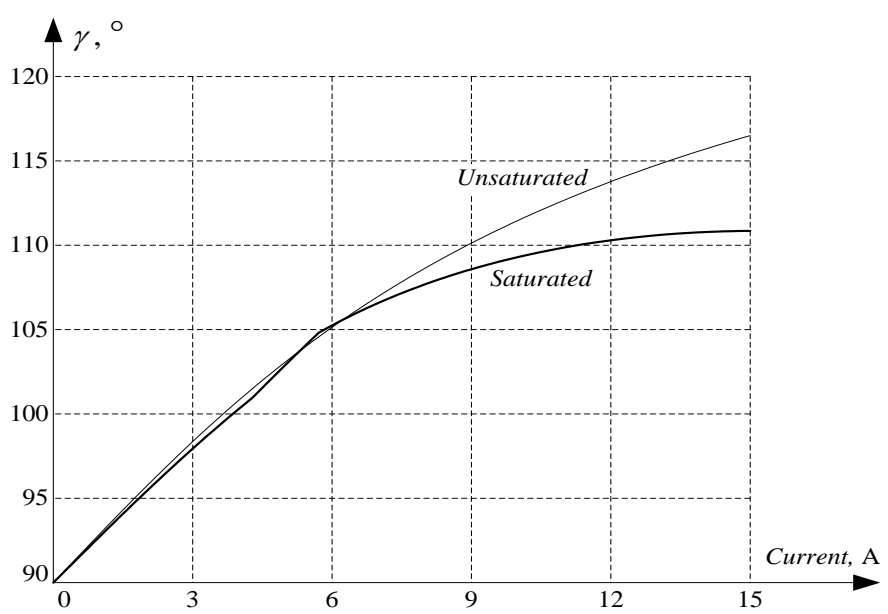

Fig. 8. MTPA angles 
tested motor is shown in the Fig. 8. It can be easily approximated by the parabola:

$$
\gamma(i)=90+i(A-i)
$$

where

\section{A -fitting coefficient.}

All parameters for the (5) and (6) have to be found experimentally at the stage of development. The best solution is to have a set of experimental points and the approximate them by the Least Square Method (LSM) finding unknown coefficients. In the developed control system motor inductances are recalculated after current sampling and before using motor model.
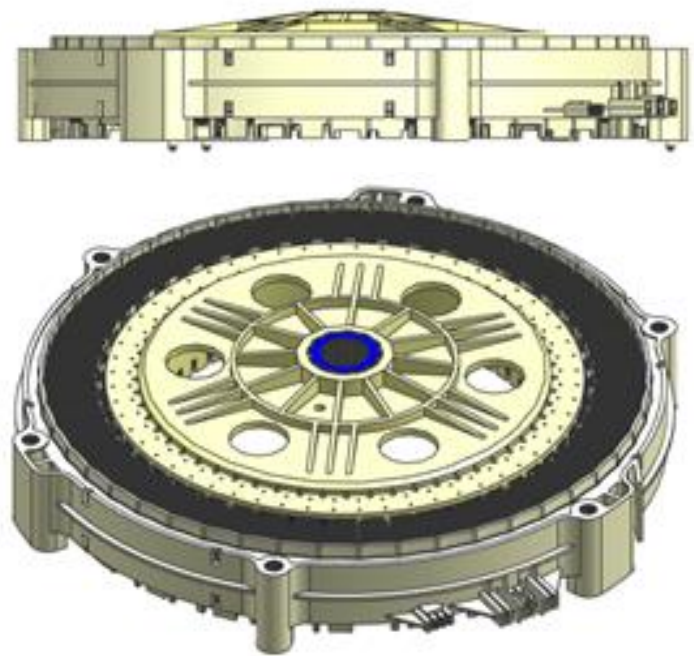

Fig. 9. Direct drive motor

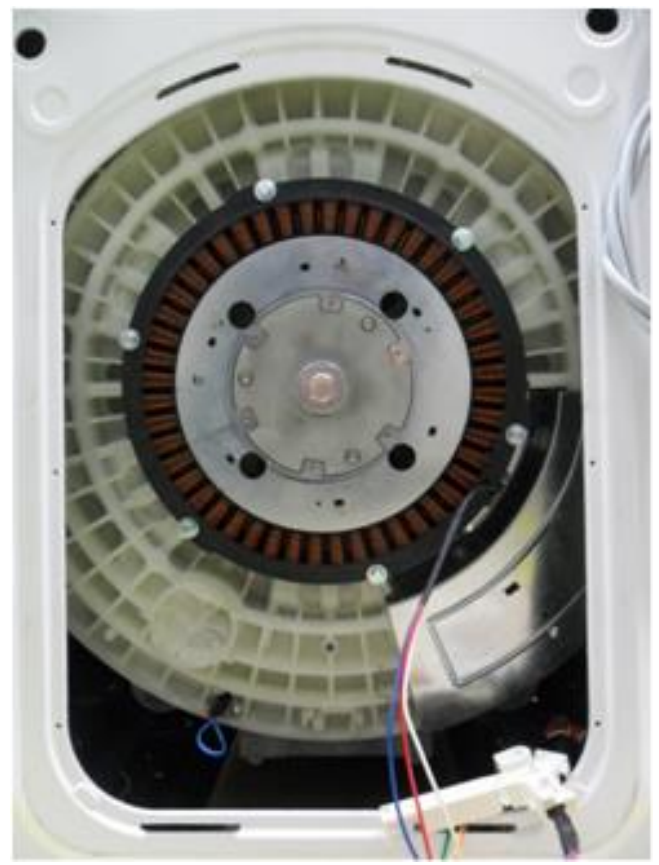

Fig. 10. Back view of the washing machine

\section{Experimental Results}

Proposed algorithm has been implemented for standard three-phased voltage source PWM inverter, which is controlled by 60 MIPS fixed point "Matsushita" microcontroller MN103SFA7K with10 kHz PWM. Serial DD washing machine for $15 \mathrm{~kg}$ laundry has been equipped with new motor and used in the experiments. Direct drive motor for the developed system is shown in the Fig. 9; same motor attached to the tub of washing machine is shown in the Fig. 10; motor parameters are given in the Table I. The developed DD has conventional control system with disbalance detection and field weakening controller, however they are not discussed in this paper.

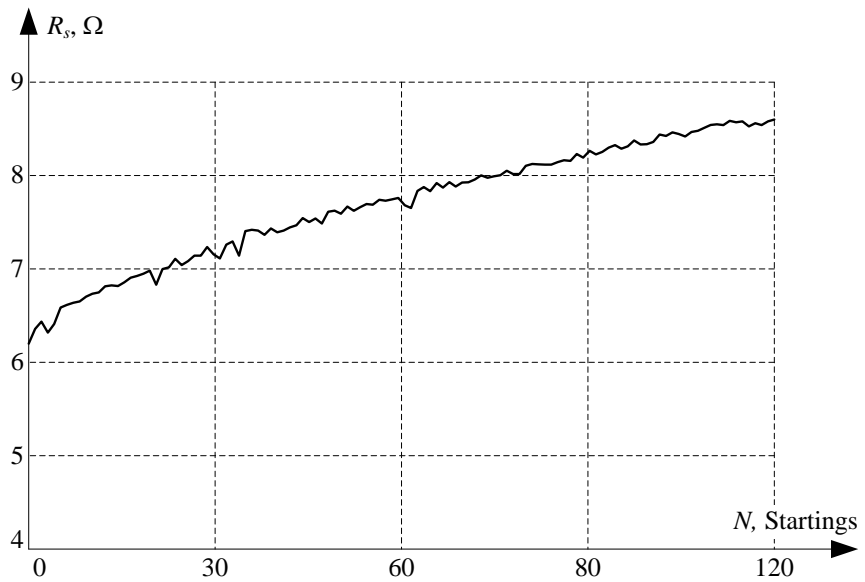

Fig. 11. Stator resistance variation
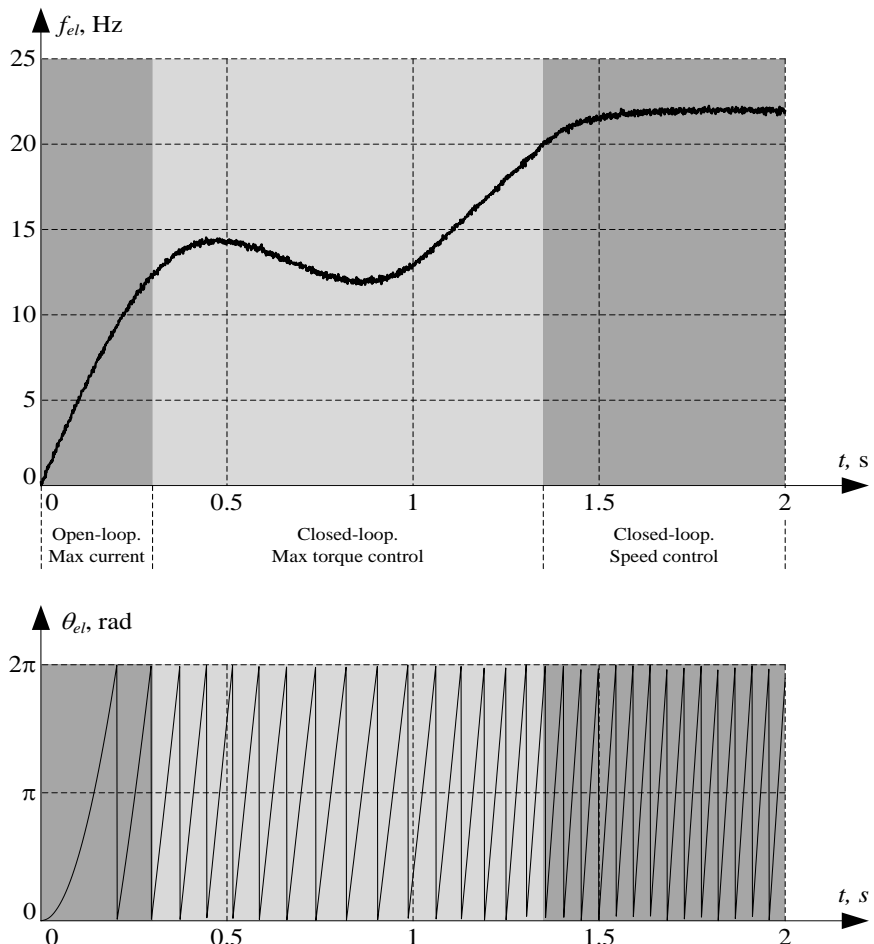

Fig. 12. Motor starting. Speed and position 


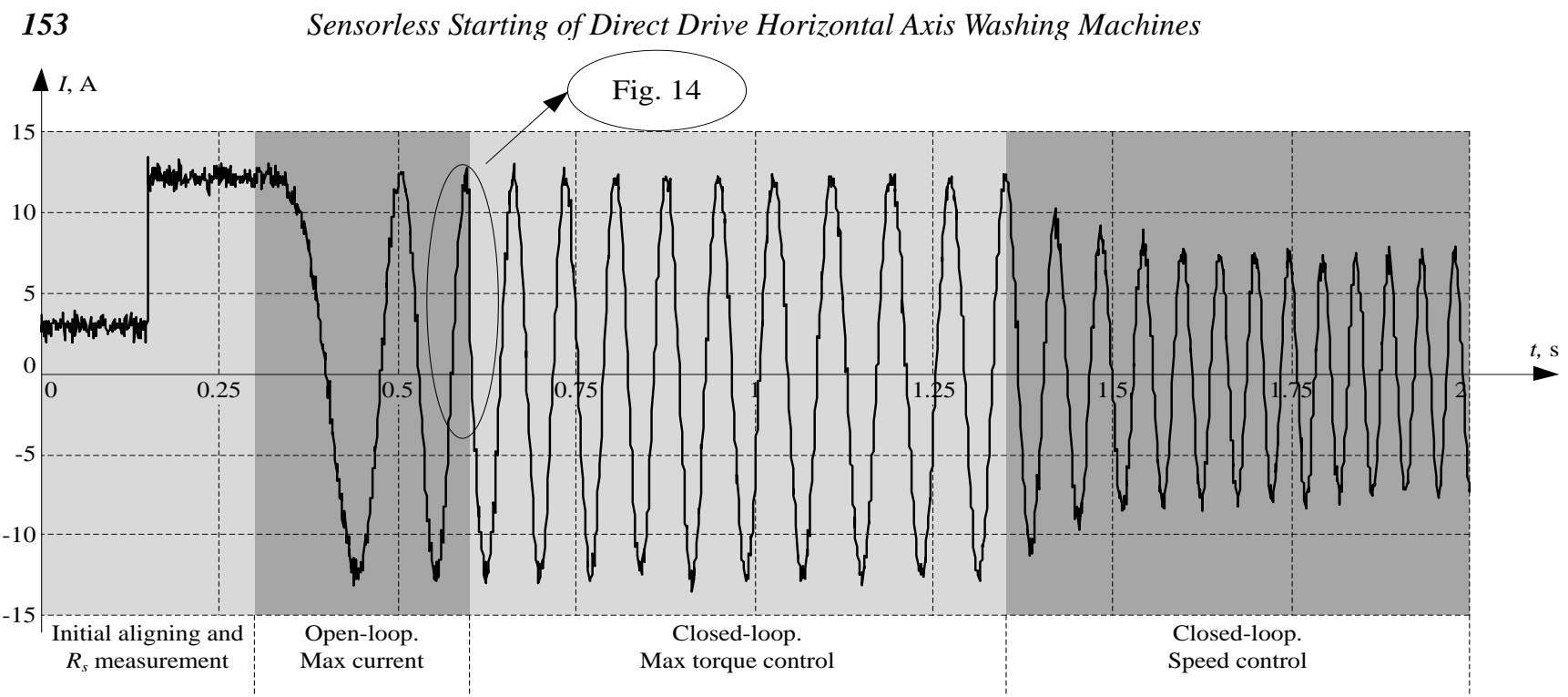

Fig. 13. Motor starting. Current waveform

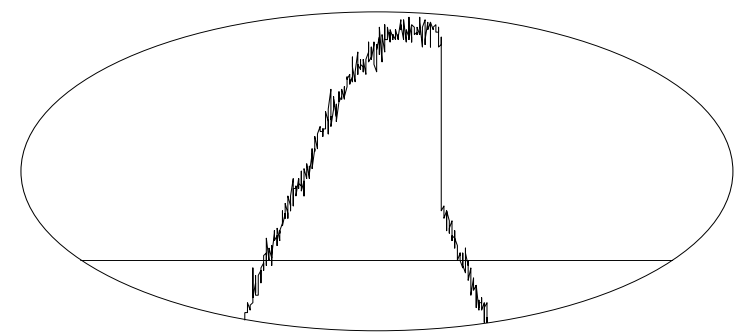

Fig. 14. Closing of the control system

For the verification of the proposed algorithm the washing machine was fully loaded with 15 kilograms of towels and 60 liters of water. The start testing sequence comprises 10 seconds of $\mathrm{CW}$ rotation at $47 \mathrm{rpm}, 10$ seconds of pause, 10 seconds of CCW rotation at $47 \mathrm{rpm}$ and 10 seconds of pause. Before every start the system performs parameters measurement and corrects motor model. The control program counts number of successful starting and fails.

Numerous experiments showed that system works well at high load in a wide range of stator temperatures with failure rate about $1 \%$, which is acceptable for such applications.

The value of the stator resistance measured before every start is shown in the Fig. 11. It corresponds to the stator temperature variation approximately from $20^{\circ} \mathrm{C}$ till $120^{\circ} \mathrm{C}$, where last number is maximum working temperature. At the same time voltage drop stayed almost unchanged and was equal to $3 \mathrm{~V}$.

Motor speed and position at starting are shown in the Fig. 12 and phase current is shown in the Fig. 13. This process can be divided into 4 stages: initial aligning, openloop starting with maximum current, closed-loop acceleration with maximum torque control and closed-loop speed control.

These four stages are shown in the Fig. 13 and three of them except initial aligning are shown in the Fig. 12 and emphasized with colors. The first stage is initial aligning. At this stage current is applied to the phase "A" and smoothly rises till its maximum. During this stage rotor of the motor is aligned along the applied field. Next stage is open-looped starting with a maximum current. At this stage maximum current along direct axis is applied to the motor and starts rotation. At the same time position estimator starts its work trying to identify position of the rotor. Since the load torque is low, when tub angle is about zero, the rotor follows the stator field lagging at small load angle. After two electrical revolutions motor speed reaches $12 \mathrm{el} . \mathrm{Hz}$, where estimator works with acceptable error. At this point control system closes, recalculate motor current and voltages in the synchronous reference frame using estimation angle and reload current and speed controllers with new values. Control systems at this point keeps current amplitude the same, but changes its phase to produce maximum torque.

This process is illustrated in the Fig. 14, which shows that phase of the stator current has been changed at one step. Proper implementation of this algorithm allows instant switching to the estimation parameters; more detailed information can be found in [8].

Following stage is closed loop acceleration with maximum torque, where control system continues acceleration and uses estimated position. During this stage load torque exceeds motor torque and causes speed fall. However it can be seen that real speed decrease in the Fig. 12 is not as big as a theoretical one in the Fig. 3, since in this interval laundry restructuring happens and load torque lowers.

The last stage is closed-loop speed control, which is activated, when motor accelerates to $20 \mathrm{el} . \mathrm{Hz}$. In this mode control system increases motor speed till $47 \mathrm{rpm}$ (about $22 \mathrm{el} . \mathrm{Hz}$ ) and keeps it constant. 


\section{Conclusions}

A new sensorless starting algorithm for horizontal axis washing machines has been developed. This algorithm takes into account numerous variations of the motor parameters, which improves performance of the position estimator at low speed and makes possible early closing of the control system. Proposed algorithm can start washing machine even if the laundry torque is higher than the motor torque and can rotate tub until laundry restructuring. The proper work of the algorithm has been verified by the series of experiments, which demonstrated low failure level.

\section{References}

[1] Song Chi, Zheng Zhang, Longya Xu, "Sliding-Mode Sensorless Control of Direct-Drive PM Synchronous Motors for Washing Machine Applications", IEEE Trans. on Industry Applications, Vol. 45, pp. 582 - 590, 2009.

[2] R. Bojoi, B. He, F. Rosa, F. Pegoraro, "Sensorless Direct Flux and Torque Control for Direct Drive washing machine applications", Energy Conversion Congress and Exposition (ECCE), pp. 347 - 354, 2011.

[3] In-Yong Ha, Jung-Hyo Lee, Jin-Ho Park, Taeck-Kie Lee, Chung-Yuen Won "IPMSM Vector Control using an I/F Initial Operating Method", International Power Electronics Conference, pp. 1393 - 1397, 2008.

[4] P. Balazovic, R. Filka, "Sensorless PMSM control for $\mathrm{H}$-axis washing machine drive", Power Electronics Specialists Conference, pp. 4237 - 4242, 2008.

[5] M. Barcaro, A. Faggion, N. Bianchi, S. Bolognani, "Sensorless Rotor Position Detection Capability of a Dual Three-Phase Fractional-Slot IPM Machine", IEEE Transactions on Industry Applications, Vol. 48, pp. 2068 - 2078, 2012.

[6] Tian-Hua Liu, Cheng-Kai Lin, Chi-Hsun Lo, "Implementation of a novel high-performance sensorless IPMSM drive for washing machines", 2010 IEEE International Conference on Industrial Technology (ICIT), pp. 367 - 372, 2010.

[7] A. Murray, M. Palma, A. Husain, "Performance Comparison of Permanent Magnet Synchronous Motors and Controlled Induction Motors in Washing Machine Applications Using Sensorless Field Oriented Control", Industry Applications Society Annual Meeting, pp. $1-6,2008$.

[8] Dianov A., Kim Young-Kwan, Lee Sang-Joon, Lee Sang-Taek, Yoon Tae-Ho, "Sensorless IPMSM based drive for reciprocating compressor", Power Electronics and Motion Control Conference, pp. $1002-1008$, 2008.
Anton Dianov received B.Sc, M.Sc and $\mathrm{PhD}$ degrees in Electrical Engineering from Moscow Power Engineering Institute (National Research University). Since 2005 he works as a Senior Engineer in Samsung Electronics. His research interests are sensorless electrical drives, control algorithms and motor drive systems.

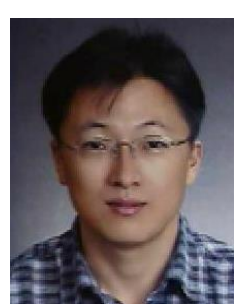

Nam Su Kim received B.Sc degrees in electrical engineering from Dongguk University and M.Sc degrees in electrical engineering from Sungkyunkwan University. Since 2000 he works as a Sr. Engineer in Samsung Electronics. His research interests are sensorless electrical drives, motor drive systems and fault protection.

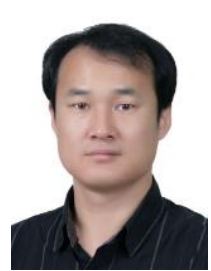

Seung Moo Lim graduated from Konkuk University in 1995. From that time he worked in Daewoo Electronics developing inverter H/W. In 2002, he joined Samsung Electronics, where he currently works as a Principal Engineer. His research interests are washing machines and control systems for the home appliances. 